\title{
Evaluation of Seismic Performance Focusing on Increasing Response of Lead Rubber Bearing (LRB) and Over Strength of RC Pier During Earthquake
}

By Naito Nobuyuki, Park Kyeonghoon, Mazda Taiji, Uno Hiroshige \& Kawakami Masahide

Kyushu University

Abstract- The characteristics of the seismic bearing change depending on various factors. When an earthquake occurs, the behavior of the bridge may differ from the values expected in the structural design. The shear deformation of the seismic bearing may increase, but it is difficult to reach the fracture deformation. This paper studied the effect of the stiffness due to various dependency and durability on Lead Rubber Bearings (LRB) and the over strength of bridge piers on the bearing behavior when an earthquake occurred. As a result, if the stiffness of LRB reduces within the criteria, seismic performance can be expected safety even if the shear strain designed in the current design is greater than the allowable shear strain. The reason is that the hardening phenomenon in the high strain region of the laminated rubber bearing suppresses the displacement. Also, since the seismic bridges with over strength of the piers have come near elastic behavior when an earthquake occurs, shear strain is easy to be large.

Keywords: rubber bearing characteristic change, hardening, lead rubber bearing, pier ductility, non-linear time history analysis, over pier strength.

GJRE-E Classification: FOR Code: 290899

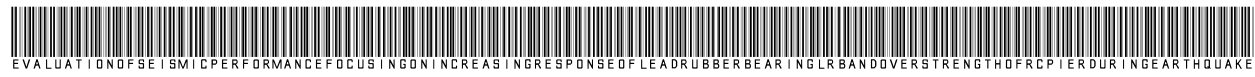

Strictly as per the compliance and regulations of:



(c) 2020. Naito Nobuyuki, Park Kyeonghoon, Mazda Taiji, Uno Hiroshige \& Kawakami Masahide. This is a research/review paper, distributed under the terms of the Creative Commons Attribution-Noncommercial 3.0 Unported License http://creativecommons.org/licenses/by-nc/3.0/), permitting all non-commercial use, distribution, and reproduction in any medium, provided the original work is properly cited. 


\title{
Evaluation of Seismic Performance Focusing on Increasing Response of Lead Rubber Bearing (LRB) and Over Strength of RC Pier During Earthquake
}

\author{
Naito Nobuyuki ${ }^{\alpha}$, Park Kyeonghoon ${ }^{\circ}$, Mazda Taiji ${ }^{\rho}$, Uno Hiroshige ${ }^{\omega}$ \& Kawakami Masahide ${ }^{*}$
}

\begin{abstract}
The characteristics of the seismic bearing change depending on various factors. When an earthquake occurs, the behavior of the bridge may differ from the values expected in the structural design. The shear deformation of the seismic bearing may increase, but it is difficult to reach the fracture deformation. This paper studied the effect of the stiffness due to various dependency and durability on Lead Rubber Bearings (LRB) and the over strength of bridge piers on the bearing behavior when an earthquake occurred. As a result, if the stiffness of LRB reduces within the criteria, seismic performance can be expected safety even if the shear strain designed in the current design is greater than the allowable shear strain. The reason is that the hardening phenomenon in the high strain region of the laminated rubber bearing suppresses the displacement. Also, since the seismic bridges with over strength of the piers have come near elastic behavior when an earthquake occurs, shear strain is easy to be large.
\end{abstract}

Keywords: rubber bearing characteristic change, hardening, lead rubber bearing, pier ductility, non-linear time history analysis, over pier strength.

\section{INTRODUCTION}

T he factors for changing the response of LRB are shown in Tab. 1. The properties of LRB vary by several factors. The actual behavior of earthquakes may be different from the expected behavior of the structural design [1]. In Tab. 1, the length of the arrow indicates the change in response. The earthquake reduces the stiffness of laminated rubber bearings and causes large shear deformation. Eventually, fracture deformation occurs beyond the allowable shear deformation [2]. However, since the hardening occurs in the high shear deformation region of the laminated rubber bearing, the resistance force is greater than when it is designed without hardening [3]. The actual displacement of the laminated rubber bearing of the structure is suppressed than the designed displacement, and it has a result that it is difficult to reach the fracture deformation. Besides, the pier has over strength, and the yield load becomes larger than the expected design. Therefore, the resistance of the pier during an earthquake is strengthened, but a large inertia force acts on the laminated rubber bearing. Moreover, a factor that increases the shear deformation of the laminated rubber bearing during an earthquake is involved statically indeterminate force due to the expansion and contraction of the girder caused by temperature changes. This paper proposes that the elongation of girders caused by expansion and contraction cannot ignore the effects of statically indeterminate force on seismic performance $[4,5]$. Also, the temperature dependency of the laminated rubber bearing at low temperatures is large [6, 7]. In continuous girder bridges, the performance of laminated rubber bearings installed in each pier differs from the design values by dispersion of inertia forces, and the inertia forces acting on specific bearings, and substructures change. For this reason, it is preferred that the laminated rubber bearing applied to the continuous girder bridges is manufactured in the same manufacturing process as possible so that there is little difference in performance among products [8]. On the other hand, because the ground conditions are different from the design expectations, there is a possibility that the seismic performance of the bridge may be lost due to changes in the characteristics of the foundation. This paper focuses on bridges with LRB that increase shear strain during an earthquake, and various cases were analyzed for this examination bridge. The details can be divided into the effect of reducing the deformation of hardening due to the stiffness reduction of LRB during an earthquake, the effect of over strength RC column type pier on the response of LRB and the effect of LRB stiffness increase or decrease in continuous girder bridge. Besides, temperature change, which is a factor in which shear strain of LRB increases, has already been shown in past papers $[4,5]$. Also, since the quantified amount of change in the foundation is uncertain and the impact of the change in the condition of the foundation is not expected to be significant when the pier is plasticized, it is not considered in this paper.

Author a: Dr. Eng., ARK Information Systems, INC., Tokyo, Japan. e-mail: Naito.nobuyuki@ark-info-sys.co.jp

Author o: Graduate student, Department of Civil Engineering, Kyushu University, Fukuoka, Japan. e-mail: khoon1103@gmail.com

Author p: Dr. Eng., Full Professor, Department of Civil Engineering, Kyushu University, Fukuoka, Japan. e-mail:mazda@doc.kyushu-u.ac.jp Author w: Dr. Eng., Professional Engineer, Ichii Consultant Co., Ltd., Japan.e-mail: huno@oak.ocn.ne.jp

Author ¥: Dr. Eng., CEO, Structural Engineering Research Institute for Disaster Prevention L.L.C, Fukuoka, Japan.

e-mail: masahide09210715@hotmail.co.jp 
Table 1: Factor for variation of response for LRB

\begin{tabular}{|c|c|c|c|c|}
\hline \multicolumn{2}{|c|}{ Factor for variation of response } & Contents of factor & Response of LRB & Note \\
\hline \multirow{2}{*}{ Durability } & $\begin{array}{l}\text { Compressive } \\
\text { fatique durability }\end{array}$ & $\begin{array}{l}\text { Ability variation by fatigue durability due to } \\
\text { repeatedly compression }\end{array}$ & $\leftarrow$ & \multirow{5}{*}{$\begin{array}{l}\text { Evaluation } \\
\text { by NEXCO }\end{array}$} \\
\hline & $\begin{array}{l}\text { Shear fatigue } \\
\text { durability }\end{array}$ & $\begin{array}{l}\text { Ability variation by fatigue durability due to } \\
\text { repeatedly shear force }\end{array}$ & $<$ & \\
\hline \multirow{3}{*}{ Stability } & $\begin{array}{l}\text { Periodic } \\
\text { dependency }\end{array}$ & $\begin{array}{l}\text { Ability variation depending on input period of } \\
\text { seismic force }\end{array}$ & $\leftarrow$ & \\
\hline & $\begin{array}{l}\text { Temperature } \\
\text { dependency }\end{array}$ & Ability variation due to ambient temperature & & \\
\hline & $\begin{array}{l}\text { Bearing } \\
\text { dependency }\end{array}$ & $\begin{array}{l}\text { Ability variation due to pressure under vertical } \\
\text { load }\end{array}$ & & \\
\hline \multicolumn{2}{|l|}{ Hardening } & $\begin{array}{l}\text { Characteristic of rubber by hardening in high } \\
\text { strain region }\end{array}$ & & $\begin{array}{l}\text { Constantly } \\
\text { appearance }\end{array}$ \\
\hline \multicolumn{2}{|c|}{ Overstrength of pier } & $\begin{array}{l}\text { Enhancement of yielding stiffness and yielding } \\
\text { load of pier due to execution, aging etc. }\end{array}$ & $\leftrightarrow$ & \\
\hline \multicolumn{2}{|c|}{$\begin{array}{l}\text { Non-static stability force due to } \\
\text { temperature change }\end{array}$} & $\begin{array}{l}\text { Influence to initial load during earthquake due to } \\
\text { non - static stability force }\end{array}$ & & \\
\hline \multicolumn{2}{|c|}{ Aging deterioration of rubber } & Hardening of rubber by aging & $\longleftrightarrow \longrightarrow$ & \\
\hline \multicolumn{2}{|c|}{$\begin{array}{l}\text { Allotment of inertia force on } \\
\text { continuous girder }\end{array}$} & $\begin{array}{l}\text { Variation of distribution of inertia force caused } \\
\text { by bearing, substructure etc. }\end{array}$ & & \\
\hline \multicolumn{2}{|c|}{$\begin{array}{l}\text { Characteristics of foundation } \\
\text { ground }\end{array}$} & Ground property exceeding assumptions & & \\
\hline
\end{tabular}

Table 2: Coefficient on calculation of $\operatorname{Cr}(\gamma)$ for LRB

\begin{tabular}{|c|c|c|c|c|}
\hline \multicolumn{2}{|c|}{ Application condition } & $\mathrm{a}_{0}$ & $\mathrm{a}_{1}$ & $\mathrm{a}_{2}$ \\
\hline$\gamma \leqq 1.75$ & Common & 1 & - & - \\
\hline \multirow{3}{*}{$1.75<\gamma \leqq 2.50$} & $\mathrm{G} 8$ & 0.905 & 0.028 & 0.015 \\
\cline { 2 - 5 } & $\mathrm{G} 10$ & 1.046 & -0.161 & 0.077 \\
\cline { 2 - 5 } & $\mathrm{G} 12$ & 1.049 & -0.203 & 0.100 \\
\hline
\end{tabular}

\section{Consideration of Factors for ANALYSIS}

\section{a) Decrease the stiffness of $\angle R B$}

In a bridge equipped with laminated rubber bearings such as isolating bearing, there is a possibility that stiffness may be reduced due to the performance differences, dependency, and durability for each product $[9,10]$. As a result, the strain of laminated rubber bearings during an earthquake is larger than expected in structural design. The East, Central, and West Nippon Expressway Co., Ltd. defined the limit value of the performance variation due to these factors as $R_{k+}$ and $R_{k-}$, and sets limits of +0.30 and -0.15 respectively [11].This value was based on the Standard Specifications for Structure Construction Management (Jul.2012) and was calculated using the formula in Appendix 1. This paper studied the case where the

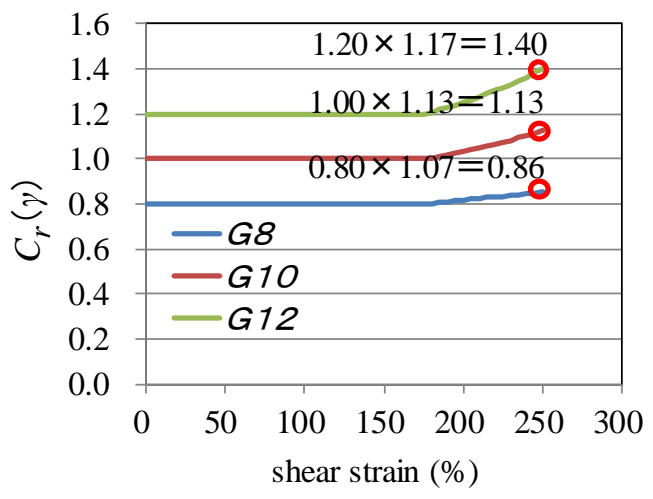

Fig. 1: $\operatorname{Cr}(\gamma)$ for LRB

shear modulus of LRB decreased by $15 \%$ as the maximum value and increased by $30 \%$ as the minimum value of the expected stiffness in LRB. In the model of piers that assumed continuous girder bridges, the effect of dispersion was also analyzed by combining the case where the stiffness of LRB between piers was increased by $30 \%$ and the rigidity of LRB was decreased by $15 \%$.

\section{b) Hardening of $L R B$}

The equivalent shear modulus of elasticity $G(\gamma)$ for shear cross-sectional deformation in consideration of hardening of LRB by Takahashi et al. is shown in equation (1) [12]. The first term $C_{r}(\gamma)$ in Eq. (1) includes the effect of stiffness increase due to hardening given in Tab. 2. Fig. 1. shows the relationship between $C_{r}(\gamma)$ and shear strain. The $C_{r}(\gamma)$ of LRB, G12 in this paper, becomes 1.17 at $250 \%$ of shear strain. The second term used $q(\gamma)$ in the Manual for Highway Bridges Bearings [2]. 
Table 3: Change of characteristic based on experiences of over strength for pier

\begin{tabular}{|c|c|c|c|c|c|}
\hline Variation factor & Variation rule & Average & $\begin{array}{c}\text { Variation } \\
\text { coefficient }\end{array}$ & Average $-\sigma$ & Average $+\sigma$ \\
\hline \hline Yielding rigidity & $\mathrm{K}_{\mathrm{PY}}{ }^{\mathrm{R}}=(1 \pm \mathrm{S}) \cdot \mathrm{AVE}\left(\mathrm{K}_{\mathrm{PY}}\right) \cdot \mathrm{K}_{\mathrm{PY}}{ }^{0}$ & 0.96 & 0.14 & 0.83 & 1.09 \\
\hline Yielding load & $\mathrm{P}_{\mathrm{PY}}{ }^{\mathrm{R}}=(1 \pm \mathrm{S}) \cdot \mathrm{AVE}\left(\mathrm{P}_{\mathrm{PY}}\right) \cdot \mathrm{P}_{\mathrm{PY}}{ }^{0}$ & 1.14 & 0.06 & 1.07 & 1.21 \\
\hline$\square^{\mathrm{R}}:$ Stochastic quantity under dispersion, $\mathrm{S}:$ Coefficient of variation, AVE : Average of dispersion \\
$\square^{0}:$ Designed value, PY: Time on yielding of pier, $\sigma:$ Standard deviation \\
\hline
\end{tabular}

200000

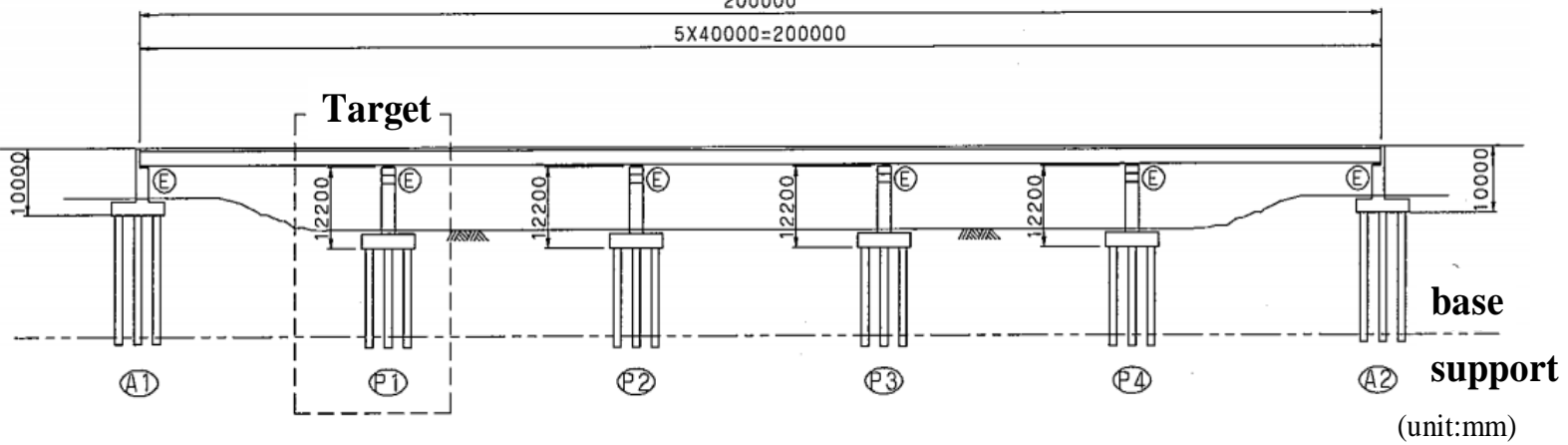

Fig. 2: General side view of examination bridge

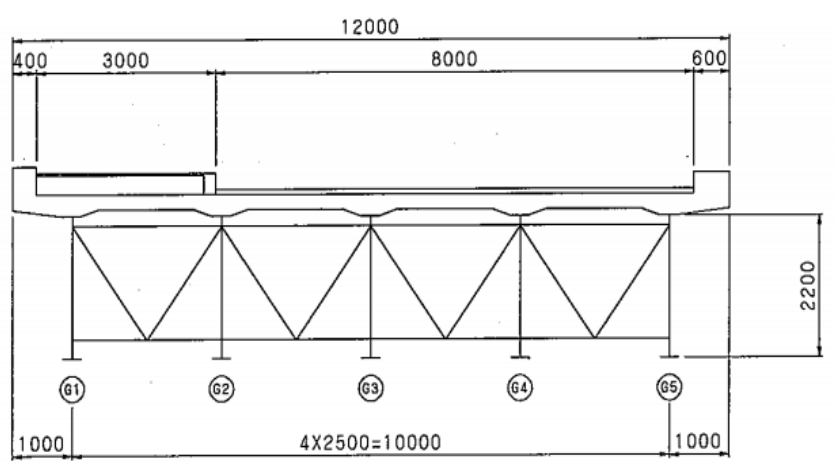

(unit:mm)

Fig. 3: Cross section of superstructure for examination bridge

$$
\mathrm{G}(\gamma)=C_{r}(\gamma) G_{e}+q(\gamma) \frac{\kappa}{\gamma}
$$

Where,

$C_{r}(\gamma)$ : Strain dependency coefficient

$G_{e}$ : Shear modulus of rubber $\left(\mathrm{N} / \mathrm{mm}^{2}\right)$

$q(\gamma)$ : Shear stress of lead plug $\left(\mathrm{N} / \mathrm{mm}^{2}\right)$

$\kappa$ : Area of lead plug / Area of rubber bearing

c) Over strength of the pier

The performance variation due to the over strength of the piers proposed by Adachi and Unjou et al. is shown in Tab. 3 [13]. This table shows the yield stiffness of the pier, the average value of the yield load, and the coefficient of variation. Here, the over strength range was set to three cases: average $-\sigma$, average, and average $+\sigma$, which has a relatively high incidence.In addition, the maximum, average and minimum values of
Table 4: Sectional component of pier

\begin{tabular}{|c|c|c|c|}
\hline \multicolumn{2}{|c|}{ Column height(m) } & \multicolumn{2}{|r|}{10.0} \\
\hline \multicolumn{2}{|c|}{ Column width(m) } & \multicolumn{2}{|r|}{5.0} \\
\hline \multicolumn{2}{|c|}{ Column thickness $(\mathrm{m})$} & \multicolumn{2}{|r|}{2.2} \\
\hline \multirow{2}{*}{$\begin{array}{c}\text { Material of } \\
\text { reinforcement }\end{array}$} & main & \multicolumn{2}{|r|}{ SD345 } \\
\hline & hoop & \multicolumn{2}{|r|}{ SD345 } \\
\hline \multirow{2}{*}{\multicolumn{2}{|c|}{$\begin{array}{l}\text { Longitudinal } \\
\text { reinforcement }\end{array}$}} & L & D38ctc125-2.0 step \\
\hline & & $\mathrm{T}$ & D38ctc125-1.0 step \\
\hline \multirow{2}{*}{\multicolumn{2}{|c|}{$\begin{array}{l}\text { Transverse restriction } \\
\text { reinforcement }\end{array}$}} & $L$ & D16ctc150, L=750 \\
\hline & & $\mathrm{T}$ & D16ctc150, L=880 \\
\hline \multirow{2}{*}{\multicolumn{2}{|c|}{$\begin{array}{l}\text { Reinforcement for shear } \\
\text { force }\end{array}$}} & L & D16-8, 150pitch \\
\hline & & $T$ & D16-5, 150pitch \\
\hline
\end{tabular}

yield stiffness and yield load occur at the same time, respectively.

\section{Bridge to Be Reviewed}

The bridge to be reviewed is located on the Type II ground listed in the Reference Design Calculation Examples of Seismic Design for Highway Bridges [14]. Fig. 2 and 3 show five spans continuous non-composite steel girder bridge. Fig. 4 shows the cross-section of the pier. This bridge is equipped with distributed rubber bearings (RB). This research replaces the bearing of the pier from RB to LRB. The crosssectional configuration of the pier was set by adjusting only the arrangement of the bar without changing the dimensions of the cross-section of the pier. The maximum shear strain of LRB is designed to $250 \%$, the 
allowable shear strain. Tab. 4 and 5 show the crosssection configuration of the pier and LRB. Also, Fig. 5 shows the historical model of the pier. Tab. 6 shows the



(a) Front view

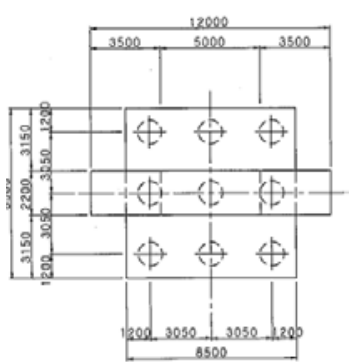

(c) Plan (unit:mm)

Fig. 4: Structural general view of pier



maximum shear strain of LRB and the maximum ductility factor of the pier.

Table 5: Sectional component and performance of LRB (/unit)

\begin{tabular}{|c|c|c|}
\hline Item & Unit & Value \\
\hline $\begin{array}{l}\text { Usable dimension (bridge axial } \\
\text { direction) }\end{array}$ & $\mathrm{mm}$ & 735 \\
\hline $\begin{array}{l}\text { Usable dimension (bridge } \\
\text { perpendicular direction) }\end{array}$ & $\mathrm{mm}$ & 735 \\
\hline Monostromatic thickness & $\mathrm{mm}$ & 32 \\
\hline Number of layers & Sheet & 4 \\
\hline Total thickness of rubber & $\mathrm{mm}$ & 128 \\
\hline Elastic shear modulus of rubber & $\mathrm{N} / \mathrm{mm} 2$ & 1.2 \\
\hline Diameter of lead plug & $\mathrm{mm}$ & 106 \\
\hline Number of lead plugs & number & 4 \\
\hline The first shape factor & - & 5.367 \\
\hline The second shape factor & - & 5.742 \\
\hline Modulus of longitudinal elasticity & $\mathrm{N} / \mathrm{mm} 2$ & 290 \\
\hline Effective area & $\mathrm{mm} 2$ & 504926 \\
\hline Area of lead plugs & $\mathrm{mm} 2$ & 35299 \\
\hline Occupation ratio of lead plugs & - & 0.070 \\
\hline Yielding load & $\mathrm{kN}$ & 294.3 \\
\hline $\begin{array}{l}\text { Shear spring constant (horizontal } \\
\text { rigidity) }\end{array}$ & $\mathrm{kN} / \mathrm{m}$ & 4734 \\
\hline $\begin{array}{l}\text { Pressure spring constant (vertical } \\
\text { rigidity) }\end{array}$ & $\mathrm{kN} / \mathrm{m}$ & 1143252 \\
\hline Shear stress of lead plug & $\mathrm{N} / \mathrm{mm} 2$ & 2.0 \\
\hline Design displacement & $\mathrm{Mm}$ & 320 \\
\hline Design strain & $\%$ & 250 \\
\hline Horizontal force & $\mathrm{kN}$ & 1584 \\
\hline First rigidity & $\mathrm{kN} / \mathrm{m}$ & 26198 \\
\hline Second rigidity & $\mathrm{kN} / \mathrm{m}$ & 4030 \\
\hline Equivalent rigidity & $\mathrm{kN} / \mathrm{m}$ & 4950 \\
\hline Equivalent damping coefficient & - & 0.113 \\
\hline
\end{tabular}

Table 6: Maximum response of pier and LRB

\begin{tabular}{|c|c|c|c|}
\hline \multicolumn{2}{|c|}{$\begin{array}{c}\text { Input } \\
\text { seismic wave }\end{array}$} & $\begin{array}{c}\text { LRB } \\
\text { maximum } \\
\text { shear strain } \\
(\%)\end{array}$ & $\begin{array}{c}\text { Pier maximum } \\
\text { ductility factor }\end{array}$ \\
\hline \multirow{4}{*}{ Type I } & I-II-1 & 128 & 0.700 \\
\cline { 2 - 4 } & I-II-2 & 119 & 0.714 \\
\cline { 2 - 4 } & I-II-3 & 110 & 0.710 \\
\cline { 2 - 4 } & Average & 119 & 0.708 \\
\hline \multirow{4}{*}{ Type II } & I-II-1 & 241 & 1.428 \\
\cline { 2 - 4 } & I-II-2 & 215 & 1.179 \\
\cline { 2 - 4 } & I-II-3 & 289 & 1.448 \\
\cline { 2 - 4 } & Average & 248 & 1.351 \\
\hline \multicolumn{2}{|c|}{ Allowable } & $250 \%(320 \mathrm{~mm})$ & $1.695(0.0449 \mathrm{~m})$ \\
\hline
\end{tabular}

Fig. 5: Hysteresis model of pier base 


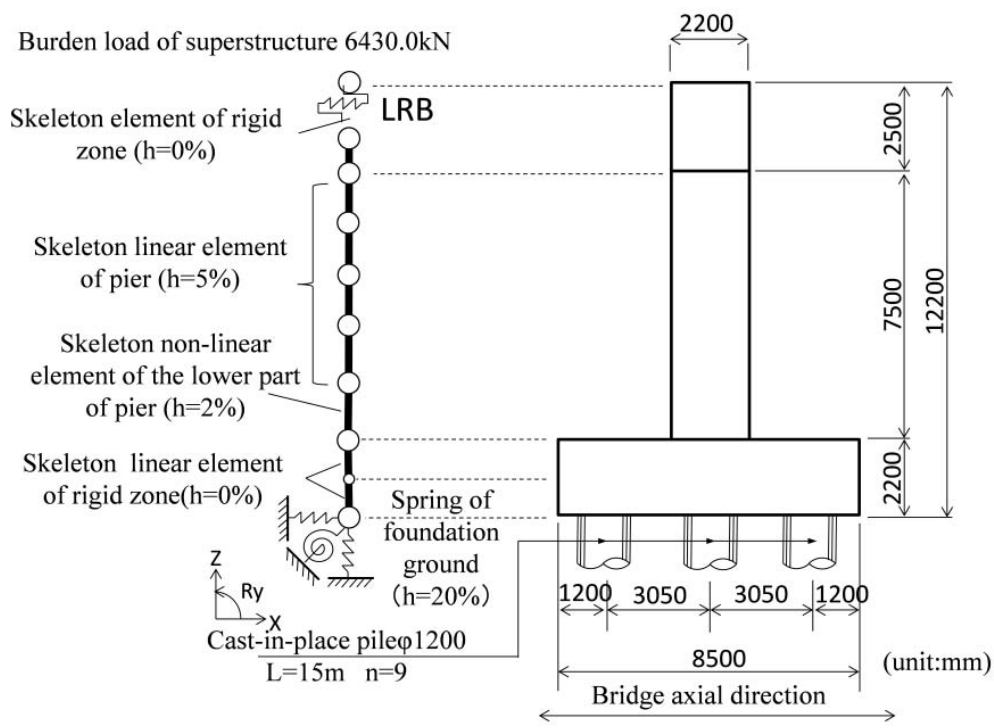

Fig. 6: Analytical model

Table 7: Table of hysteresis model

\begin{tabular}{|c|c|c|c|c|c|c|}
\hline Application & $\begin{array}{l}\text { High strain } \\
\text { region }\end{array}$ & $\begin{array}{l}\text { Hysteresis } \\
\text { shape }\end{array}$ & $\begin{array}{l}\text { Setting of shear modulus } \\
\text { of rigidity }(\mathrm{N} / \mathrm{mm} 2)\end{array}$ & $\begin{array}{c}\text { Resistance } \\
\text { force on } \\
250 \%(\mathrm{kN})\end{array}$ & \multicolumn{2}{|c|}{ Abbreviation } \\
\hline \multirow{2}{*}{$\begin{array}{l}\text { Handbook } \\
\text { of bearing }\end{array}$} & \multirow{2}{*}{ Linear } & \multirow{4}{*}{$\begin{array}{l}\text { Bilinear } \\
\text { model }\end{array}$} & 1.2 & 1,584 & $\mathrm{H}-\mathrm{Li}-\mathrm{Bi}-1.0$ & \multirow{8}{*}{$\begin{array}{l}\text { H: handbook } \\
\text { L: literature } \\
\text { Li: linear } \\
\text { HD: } \\
\text { hardening } \\
\text { Bi: bilinear } \\
\text { Tri: trilinear } \\
\text { 1.0: non-rigid } \\
\text { reduction } \\
0.85 \text { : rigid } \\
\text { reduction- } \\
15 \%\end{array}$} \\
\hline & & & $1.2 \times 0.85=1.02$ & 1,357 & H-Li-Bi-0.85 & \\
\hline \multirow{4}{*}{$\begin{array}{l}\text { Conformity } \\
\text { to handbook } \\
\text { of bearing* }\end{array}$} & \multirow{6}{*}{ Hardening } & & $1.2 \times 1.17=1.404$ & 1,842 & $\mathrm{H}-\mathrm{HD}-\mathrm{Bi}-1.0$ & \\
\hline & & & $1.2 \times 0.85 \times 1.17=1.1934$ & 1,576 & $\begin{array}{c}\mathrm{H}-\mathrm{HD}-\mathrm{Bi}- \\
0.85\end{array}$ & \\
\hline & & \multirow{2}{*}{$\begin{array}{l}\text { Trilinear } \\
\text { model }\end{array}$} & $1.2 \times 1.17=1.404$ & 1,842 & H-HD-Tri-1.0 & \\
\hline & & & $1.2 \times 0.85 \times 1.17=1.1934$ & 1,576 & $\begin{array}{c}\text { H-HD-Tri- } \\
0.85\end{array}$ & \\
\hline \multirow{2}{*}{ Literature } & & \multirow{2}{*}{$\begin{array}{l}\text { Bilinear } \\
\text { model }\end{array}$} & $1.2 \times 1.17=1.404$ & 1,836 & L-HD-Bi-1.0 & \\
\hline & & & $1.2 \times 0.85 \times 1.17=1.1934$ & 1,571 & L-HD-Bi-0.85 & \\
\hline
\end{tabular}

※Conformity means including hardening behavior for handbook

\section{Review Conditions}

In this paper, the purpose of this research is to understand the effect of LRB stiffness reduction on single pillar pier upporting superstructure and the effect for dispersion of inertia force by combined decrease and increase of LRB stiffness on multi-pier during an earthquake. For reference, column type piers and wall type piers are representative types of piers. In this research, the column type pier is used as an analysis model. Fig. 6 shows the structural model for the analysis. This structural model is the single pillar supporting beam of the bridge under review in Fig. 2. The analysis method is a nonlinear time historical response analysis. The input seismic waves were three waves of each Type I and Type II seismic wave in the Design Specifications for Highway Bridges part 5, Seismic Design and evaluated by the average of the responses from the three different waves [1].

\section{EFFect of Hysteresis}

\section{Characteristics by Reducing the}

\section{STIFFNESS OF LRB}

\section{a) Conditions of $\angle R B$ hysteresis}

The analysis that applies the history set in manual for Highway Bridges Bearings to the hysteresis characteristic of LRB is called the current design. The stiffness, which was decreased by $15 \%$ of LRB, was designed to 0.85 times the shear modulus of the rubber. The resistance force of the laminated rubber of $\mathrm{G} 12$ increased by hardening is $1.2 \times 1.17=1.40 \mathrm{~N} / \mathrm{mm}^{2}$ calculated in Fig. 1 with a shear strain of $250 \%$. The bilinear and trilinear models are typical models considering the hardening of laminated rubber bearings. The bilinear model has a history that LRB behaves as a secondary stiffness concerning a working load equal to or higher than the yield load in the same way as the current design. The trilinear model assumes that the 
hardening occurs when the shear strain of the bilinear model is $175 \%$ or more, and the resistance is a history that increases linearly with respect to the shear strain. Also, comparison by analysis using the setting formula of LRB proposed by Takahashi et al. was also conducted [12]. The Tab. 7 shows the combinations used for the review. The hysteresis characteristics of the laminated rubber and lead plugs, which are the results obtained from the analysis, are superimposed and shown in Fig. 2. That is, in the region where the deformation is small, the hysteresis of the lead plug is the main.After the lead plug yields, the resistance force increases linearly due to the shear elasticity of the laminated rubber. These hysteresis characteristics were designed in the form of bilinear or trilinear. Fig. 7 shows a comparison of the history of LRB used in the analysis. The maximum shear strain was set at $250 \%$. Convergence analysis using the hysteresis of the maximum shear strain obtained in the analysis is not performed. (a) shows all the cases and (b), (c), (d), (e) show the case where there is no stiffness drop for each hysteresis characteristic and the case where the stiffness decreases by $15 \%$, respectively.

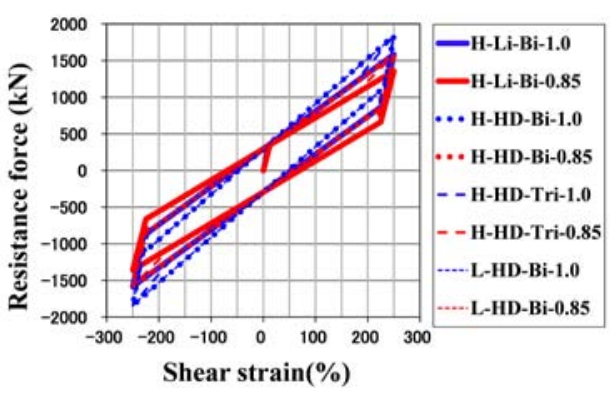

(a) All hysteresis mode

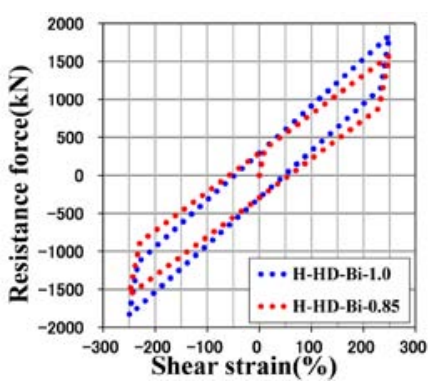

(c) HD-Bi and $15 \%$ rigid reduction on current design

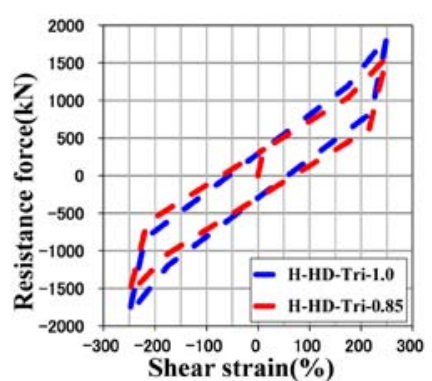

(d) HD-Tri and $15 \%$ rigid reduction on current design

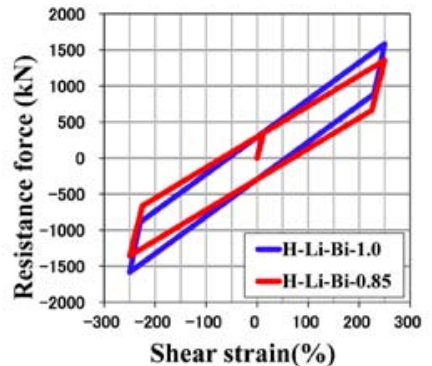

(b) $-15 \% \mathrm{Li}-\mathrm{Bi}$ and $15 \%$ rigid reduction on current design

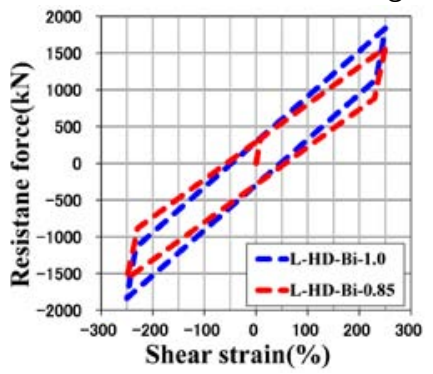

(e) L-HD-Tri and $15 \%$ rigid reduction on literature design

\section{Fig. 7: Comparison of hysteresis models}

\section{b) Analysis results}

Fig. 8 shows the maximum shear strain of LRB and the maximum ductility factor of the pier due to the difference in stiffness and hysteresis of LRB. Fig. 9 and Fig. 10 show the response history of LRB and the lower part of the pier by seismic waves $\|-\|-1$, respectively.

\section{c) Effect of the hardening on current design}

The maximum shear strain of $L R B$, the response history of LRB, and the response history of the lower part of the pier are shown in Fig. 11. To understand the effects of hardening, a bilinear model and a trilinear model considering current design and hardening design were applied. When the analysis is performed using a bilinear model in consideration of the hardening, the maximum shear strain is reduced to $200 \%$. In contrast, when analyzed using a trilinear model, it is as small as $230 \%$, which is larger than the bilinear model and smaller than the current design. In the response history, the resistance force of LRB is large in the order of current design, hardening of the bilinear model, and hardening of the trilinear model. Likewise, the curvature of the lower part of the pier shows the same order.

\section{d) Effect of the hardening on the current design and} $15 \%$ decrease in stiffness

The cases where the stiffness is reduced by $15 \%$, current design, the maximum shear strain of LRB, the hysteresis of $L R B$ response, and the response of the lower part of the pier in consideration of hardening are shown in Fig. 12. In the current design, the maximum shear strain of LRB is $250 \%$, but when the stiffness decreases by $15 \%$, the maximum shear strain may increase to $300 \%$, resulting in fracture deformation. However, because the shear strain of LRB is suppressed by hardening, the maximum shear strain in the bilinear model is $250 \%$, which is equivalent to the current design. In contrast, in the trilinear model, the 
maximum shear strain is $270 \%$, which is larger than the current design. Therefore, in actual design, it is necessary to consider the effect of the difference in the modeling of the hardening on the response.

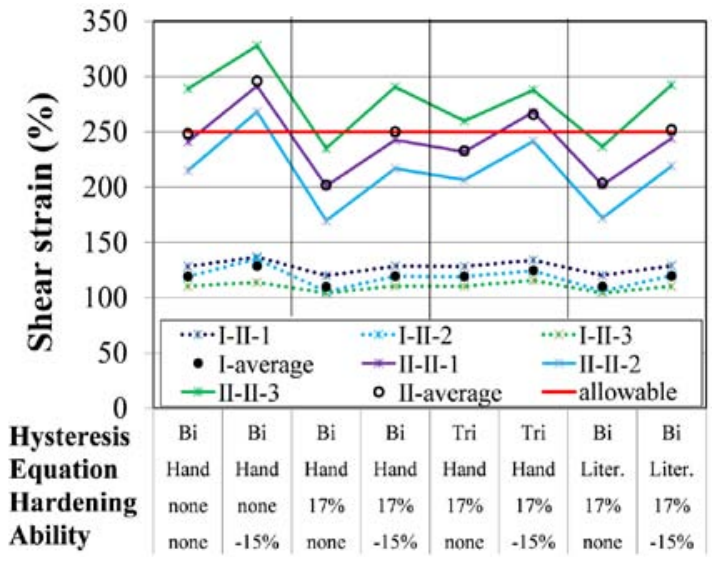

(a) Maximum shear strain of LRB

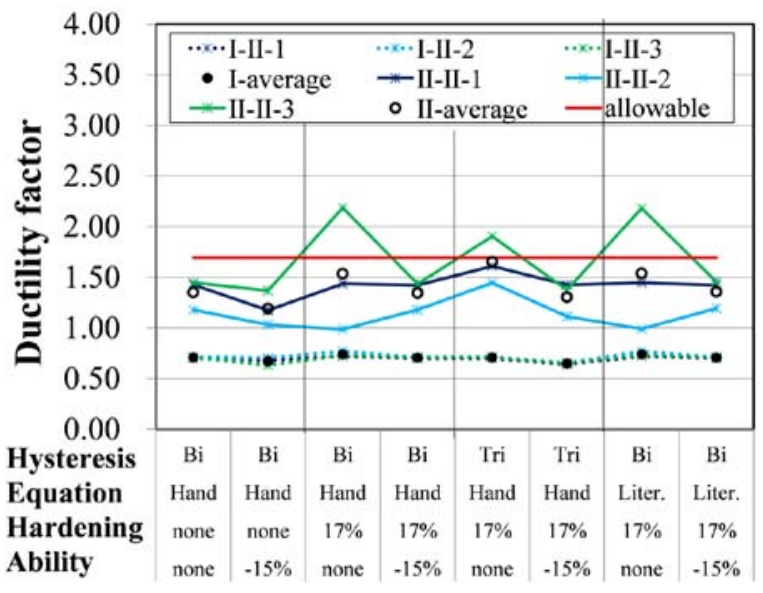

(b) Maximum ductility ratio of pier

Fig. 8: Response by rigid reduction and hysteresis model of LRB

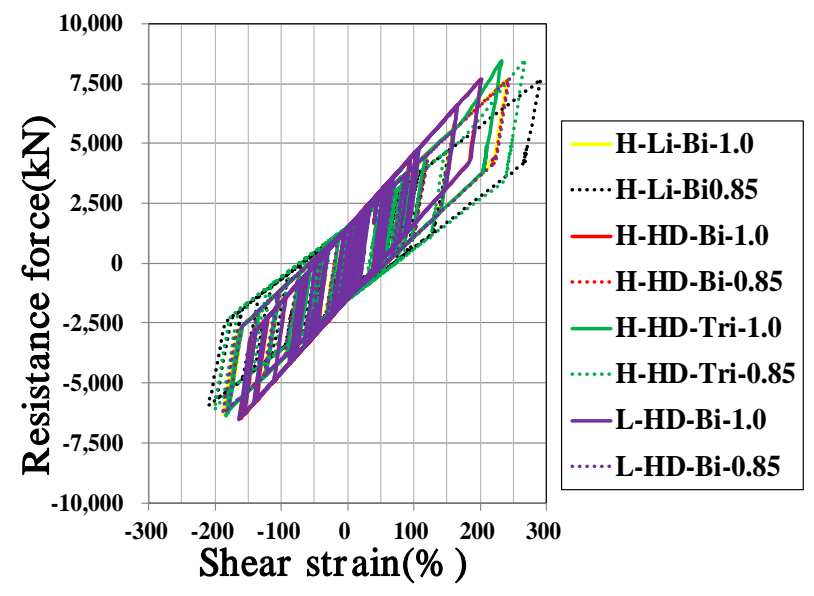

Fig. 9: Response hysteresis of LRB (II-II-1)



Fig. 10: Response hysteresis of pier base (II-II-1)



(a)Maximum shear strain of LRB

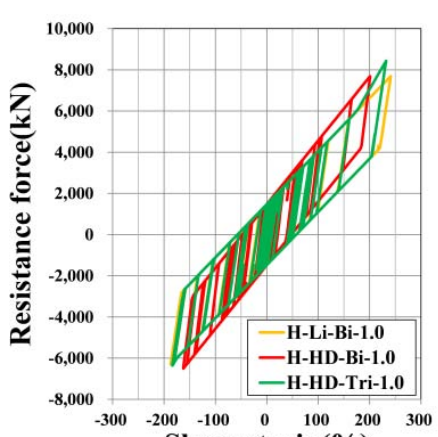

(b) Response strain hysteresis on LRB



(c)Response curvature hysteresis on LRB

Fig. 11: Effect of hardening on current design 


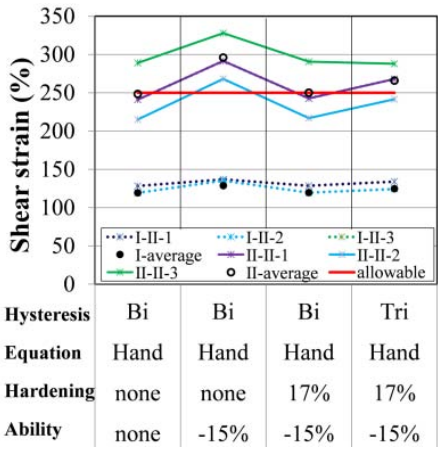

(a)Maximum shear strain of LRB



(b)Response strain hysteresis on LRB

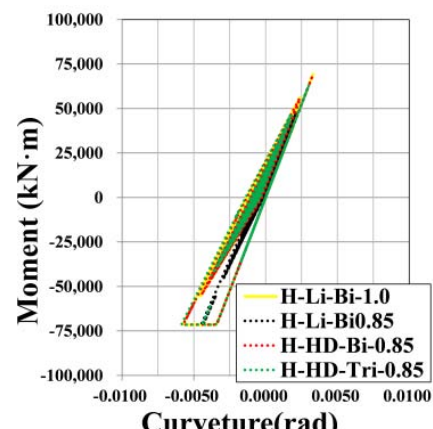

(c)Response curvature hysteresis on LRB

Fig. 12: Effect of hardening on current design and $15 \%$ stiffness rigid reduction

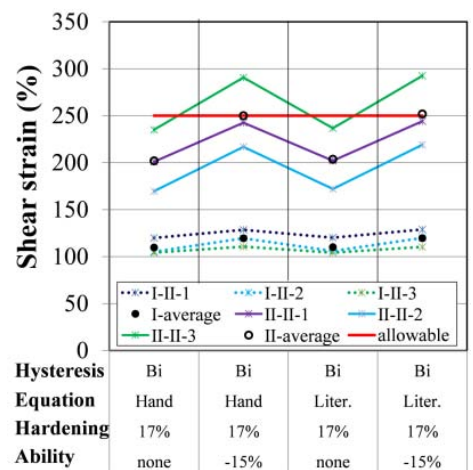

(a) Maximum shear strain of LRB

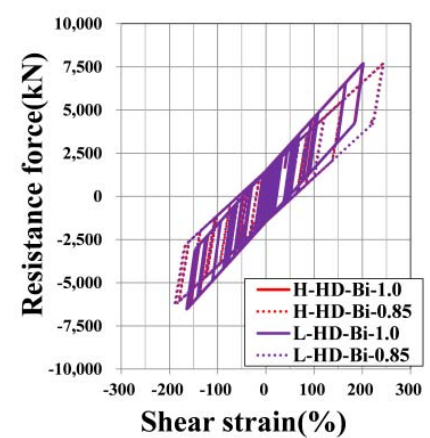

(b) Response strain hysteresis on LRB



(c) Response curvature hysteresis on LRB

Fig. 13: Effect of hardening and literature model on current design

e) Comparison of the response on hardening model and current design

The comparison of the hardening model and the response of the current design is shown in Fig. 13(a). Fig. 13(b) and (c) show the maximum shear strain of $L R B$, response history of $L R B$, and response history of the lower part of the pier when stiffness drop occurs by $15 \%$. The maximum shear strain of LRB is $250 \%$ in the current design and $300 \%$ when the stiffness is reduced by $15 \%$. In this paper, the maximum shear strain and LRB response history are the same as those of the current design, but the curvature history of the lower part of the pier is slightly different. This is because the rubber dependence coefficient $C_{r}(\gamma)$ applied in the process of setting the hardening of the current design is equal to the value set in this paper. However, since the coefficient $q(\gamma)$ for the lead plugs in the current design uses the values given in Manual for Highway Bridges Bearings, it is considered that the response of this paper and the current design may differ depending on the lead area ratio setting of LRB.

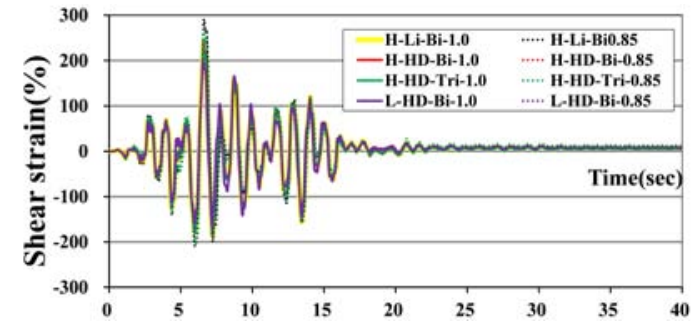

(a) From 0 to 40 seconds

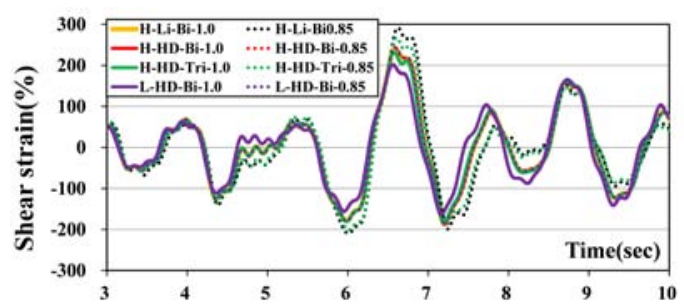

(b) From 3 to 10 seconds

Fig. 14: Shear strain responsive wave of LRB (II-II-1) 




(a)From 0 to 40 seconds

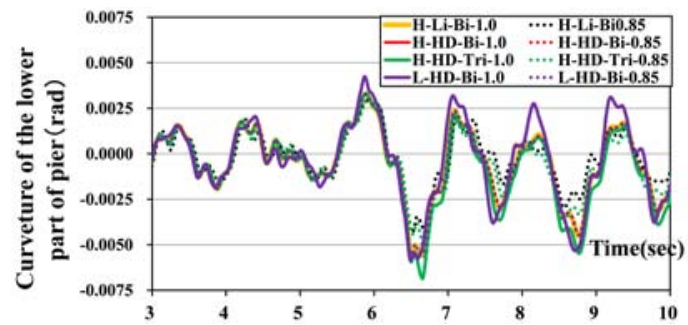

(b)From 3 to 10 seconds

Fig. 15: Curvature responsive wave of pier base (II-II-1)

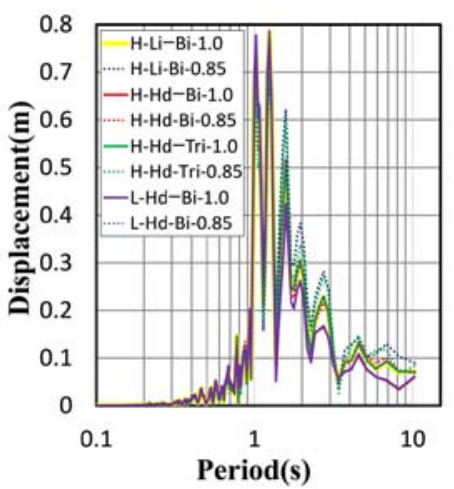

(a) II-II-1

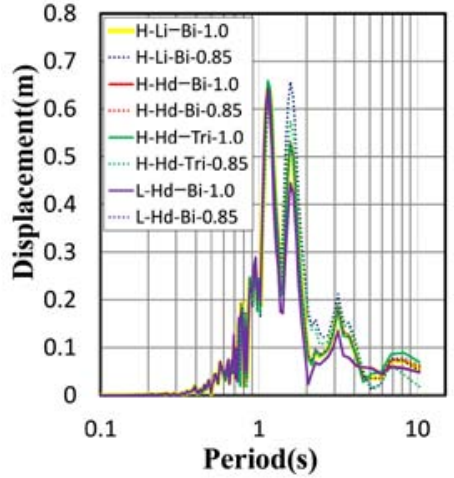

(b) II-II-2

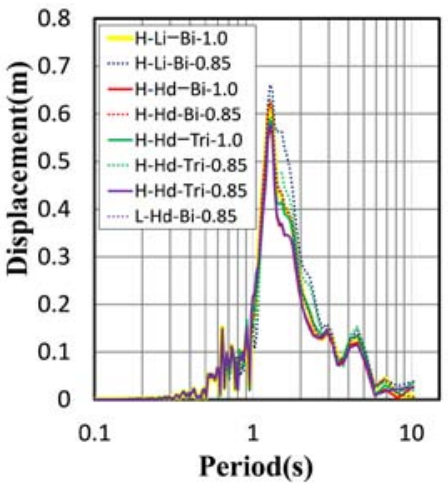

(c)II-II-3

Fig. 16: Fourier spectrum responsive displacement of superstructure

f) Time history response waveform and period characteristics

Fig. 14 and 15 show the time history response waveforms of shear strain in LRB and curvature of the lower part of the pier when II-II-1 seismic waves are input. Fig. 14(b) enlarges the response of the main behavior, 3 to 10 seconds. The response waveform for each LRB history shape is almost the same regardless of the history shape. However, the difference in the maximum response value is shown around 6.5 seconds. When the stiffness decreased by $15 \%$, it was confirmed that the shear deformation of LRB was larger, and the response period was longer. The maximum shear strain of LRB decreases due to the effect of hardening, but when the hardening is represented by the trilinear model, the maximum yielding load of the pier becomes large. In addition, at $175 \%$ shear strain, the stiffness of the rubber changes rapidly in the trilinear model, but the shear strain of LRB is not large, and a slight change in curvature of the lower part of the pier can be seen. Fig. 16 shows the Fourier spectrum due to the displacement of the superstructure to determine the period. Each earthquake waves are predominant during the same period regardless of LRB recording characteristics and reduction in stiffness. In $\|-\|-1$, there are three predominant period ranges, in II-II-2, two predominant period ranges, and in II-II-3, a single period range is widely distributed. The reason why the predominant period range is different for each wave is due to the characteristics of the input wave and the nonlinearity of
LRB and the pier. Fig. 17 shows the period with the maximum value of the Fourier spectrum in each predominant period region. In II-II-1 waves, the period is most predominant at approximately 1.241 seconds. On the contrary, the current design with the bilinear model, which is a model with hardening under constant stiffness, and in case there is a predominant as well at a shorter period of 1.024 seconds. In the II-II-2 wave, the predominant period appears at around 1.138 seconds, but in the current design that does not consider hardening at a stiffness drop of $15 \%$, the predominant period appears at 1.575 seconds. In the II-II-3 wave, the period is mostly same predominant in all cases at 1.280 seconds. This predominant response period should be considered based on not only the difference in seismic waves but also the difference in hysteresis due to stiffness reduction or hardening.

\section{g) The difference in response between the bilinear model and the trilinear model}

Fig. 18(a) shows the comparison of the history of the bilinear model of LRB and the trilinear model. These models are nonlinear models considering the hardening phenomenon of LRB. The same resistance force was designed at $250 \%$ of shear strain, but the result of the response history by the same seismic wave is different. Fig. 18(b) and 18(c) show the response results of LRB (HD-Bi-1.0, HD-Tri-1.0) without stiffness drop and LRB (HD-Bi-0.85, HD-Tri-0.85) with stiffness drop by inputting seismic wave II-II-1. As a result, there 
was a remarkable difference in the response history of LRB between the bilinear model and the trilinear model, and the trilinear model showed a larger shear strain than the bilinear model. This reason can be confirmed from each set history shown in Fig. 18. The resistance of LRB increases with increasing maximum shear strain. As shown in Fig. 18(b), when the maximum shear strain is less than $250 \%$, the resistance force of the trilinear model is less than that of the bilinear model when the shear strain is the same. This means that with the same resistance force, the shear deformation of the trilinear model becomes larger than that of the bilinear model. The maximum shear strain of the hysteresis set in this analysis is $250 \%$. Since this is different from the maximum shear strain in the results of the dynamic analysis, clearly the trilinear model cannot be a large response unless the maximum shear strain to determine the hysteresis converges. The maximum shear strain of the bilinear model is about $250 \%$ of the response history of LRB with reduced stiffness of $15 \%$ shown in Fig. 18(c). Since this shear strain is consistent with the value set in the analysis, there is no need to reset the hysteresis shape due to the maximum shear strain. On the contrary, since the response history of the trilinear model is larger than $250 \%$, it is necessary to converge the history shape to the response history. At this point, the response of the trilinear model is larger than that of the bilinear model. Likewise, it can be seen that the response of the trilinear model is greater for the curvature of the lower part of the pier in Fig. 11.

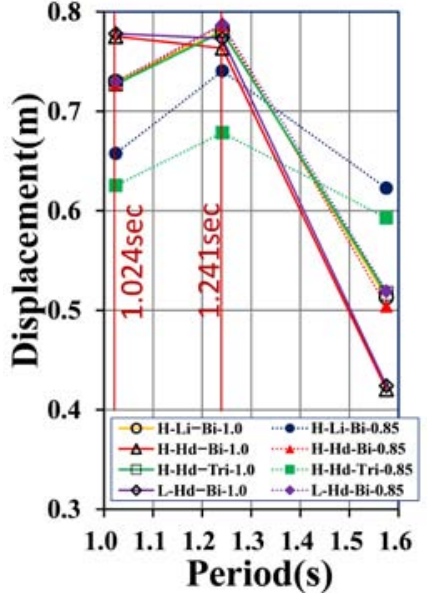

(a)II-II-1

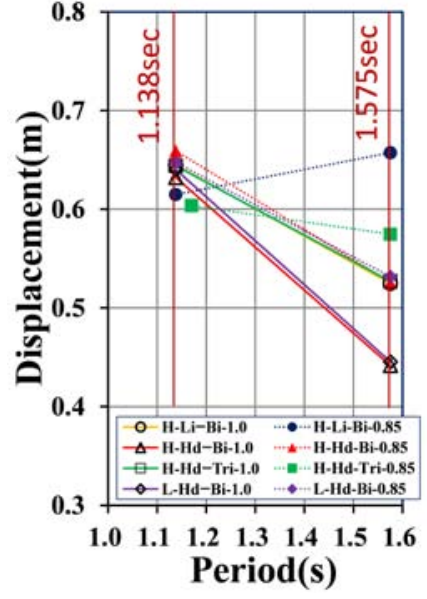

(b) II-II-2

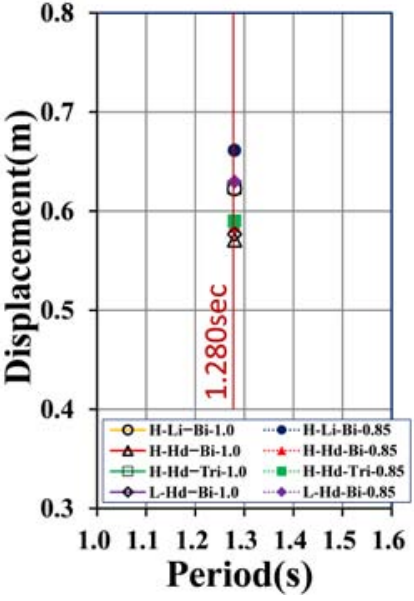

(c) II-II-3

Fig. 17: Period at the time of maximum Fourier spectrum on predominant response



(a)Basic hysteresis on $250 \%$



(b)H-HD-Bi-1.0 and H-HD-Tri-1.0

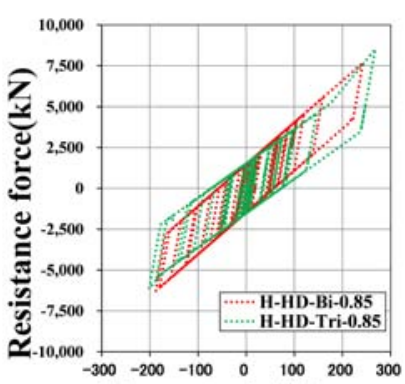

Shear strain $(\%)$

(c)H-HD-Bi-0.85 and H-HD-Tri-0.85

Fig. 18: Basic hysteresis of bilinear model and trilinear model (250\%, II-II-1)

\section{h) Response waveform and predominant period}

Tab. 8 shows the maximum values of displacement and resistance force at the time of maximum shear strain in Fig. 14. In addition, this table contains the equivalent damping ratio for the response history of the bilinear model and the trilinear model, and the correction factor for each equivalent damping ratio. The absorbed energy was calculated as the historic area of one cycle. Fig. 19 shows the energy absorbed by LRB during inputting the seismic wave. When calculating the equivalent damping constant, the strain energy was adjusted to an average value so that the starting point and the ending point could be one cycle. The absorbed energy is large in the trilinear model, but the equivalent damping constant is large in the bilinear model. The reason is that the resistance force and theelastic energy of the trilinear model are relatively larger than the bilinear model in the same shear strain. 
The correction factor for each equivalent damping constant is slightly larger in the bilinear model as
0.014.Still it does not indicate a difference in the decrease in response due to the damping performance.

Table 8: Hysteresis of bilinear model and trilinear model (II-II-1)

\begin{tabular}{|c|c|c|c|c|c|c|c|c|}
\hline & Time & Displacement & $\begin{array}{l}\text { Resistance } \\
\text { force }\end{array}$ & $\begin{array}{c}\text { Absorbed } \\
\text { energy } \\
\Delta \mathrm{W}\end{array}$ & $\begin{array}{c}\text { Equivalent } \\
\text { damping } \\
\text { constant, } \\
\mathrm{h} \\
\end{array}$ & \multirow{2}{*}{$\begin{array}{c}\text { Correction } \\
\text { factor } \\
\text { based on } \\
\text { damping } \\
\text { constant, } \\
\text { CD } \\
\end{array}$} & $\begin{array}{l}\text { Equivalent } \\
\text { damping } \\
\text { constant } \\
\text { at } 250 \%, \mathrm{~h}\end{array}$ \\
\hline & & $\mathrm{sec}$ & $\mathrm{m}$ & $\mathrm{kN}$ & $\mathrm{kN} \cdot \mathrm{m}$ & $\%$ & & $\%$ \\
\hline \multirow{3}{*}{$\begin{array}{l}\text { H-HD- } \\
\text { Bi-1.0 }\end{array}$} & $\begin{array}{l}\text { Time on minimum } \\
\text { response just before } \\
\text { maximum response }\end{array}$ & 5.95 & -0.199 & $-6,286$ & \multirow{3}{*}{$1,335.2$} & \multirow{3}{*}{13.0} & \multirow{3}{*}{0.743} & \multirow{3}{*}{10.7} \\
\hline & $\begin{array}{c}\text { Time on maximum } \\
\text { displacement }\end{array}$ & 6.56 & 0.257 & 7,684 & & & & \\
\hline & $\begin{array}{l}\text { Time on minimum } \\
\text { response just after } \\
\text { maximum response }\end{array}$ & 7.16 & -0.208 & $-6,502$ & & & & \\
\hline \multirow{3}{*}{$\begin{array}{l}\text { H-HD- } \\
\text { Tri-1.0 }\end{array}$} & $\begin{array}{l}\text { Time on minimum } \\
\text { response just before } \\
\text { maximum response }\end{array}$ & 5.98 & -0.231 & $-6,211$ & \multirow{3}{*}{$1,508.1$} & \multirow{3}{*}{12.1} & \multirow{3}{*}{0.757} & \multirow{3}{*}{10.2} \\
\hline & $\begin{array}{c}\text { Time on maximum } \\
\text { displacement }\end{array}$ & 6.57 & 0.297 & 8,436 & & & & \\
\hline & $\begin{array}{l}\text { Time on minimum } \\
\text { response just after } \\
\text { maximum response }\end{array}$ & 7.20 & -0.235 & $-6,358$ & & & & \\
\hline
\end{tabular}

i) Consideration of $L R B$ stiffness drop and response history in design

The average of three seismic waves was evaluated in the current design. Depending on the seismic wave, there were some cases where the shear strain was greater than $250 \%$. In particular, Fig. 11-(a) shows that the shear strain is about $290 \%$ in II-II-3 of the current design. This means that the shear strain of LRB exceeds $250 \%$ and approaches the fracture strain. On the contrary, when analyzed with a bilinear model considering hardening, the maximum shear strain among the three seismic waves is about $230 \%$. Since it is within $250 \%$ of the allowable shear strain, the analysis results can be sufficiently reliable. Therefore, after analyzing the response of LRB in the current design, it is better to verify it using a bilinear model that considers the hardening and to confirm the fact that the shear strain of LRB is less than $250 \%$. On the other hand, the trilinear model can be used to analyze the hardening phenomenon, but before that, it is necessary to verify the validity of the tertiary stiffness of LRB in the shear strain exceeding $250 \%$.

\section{The Impact of over Strength of Pier on Response}

\section{a) Setting of the pier}

To confirm the impact of the over strength of the pier on the response during an earthquake, a pier with a small plasticization with a maximum ductility factor of 1.351 (abbreviation as pier with $\mu=1.351$ ) used in Tab. 6 and two piers with a ductility factor of 2.005 and 3.316 (abbreviation as pier with $\mu=2.005, \mu=3.316$ ) were added. Tab. 9 shows the conditions of these three piers and each set LRB. A pier with a high ductility factor was added to investigate the effect of plasticization due to over strength of piers on the behavior of LRB during an earthquake. The maximum ductility factor of the added pier does not satisfy the allowable ductility factor, but the purpose is to understand the effect of the high ductility factor due to over strength on the pier. In this paper, pier characteristics were determined based on the amount of change in over strength. The characteristics of the pier were divided into 4 cases: the 'standard value' without considering the over strength, the 'average value' with the over strength considered, and finally, the ' $\pm \sigma$ ' considering the standard deviation. Also, the yield stiffness and yield load of the pier were set in the order of standard value, $-\sigma$, average value, and $+\sigma$. The ratio of yield load was set to 1.00: 1.07: 1.14: 1.21 .

\section{b) Analysis result}

The maximum shear strain of LRB and the maximum ductility factor of the pier with seismic waves of level 2 seismic Type I and Type II are shown in Fig. 20. The horizontal axis represents the yield stiffness and yield load of each pier. In addition, even when the pier has an elastic response, the value obtained by dividing the maximum displacement of the pier by the yield displacement was defined as the ductility factor. The over strength is evaluated as the average of the responses by three seismic waves. 


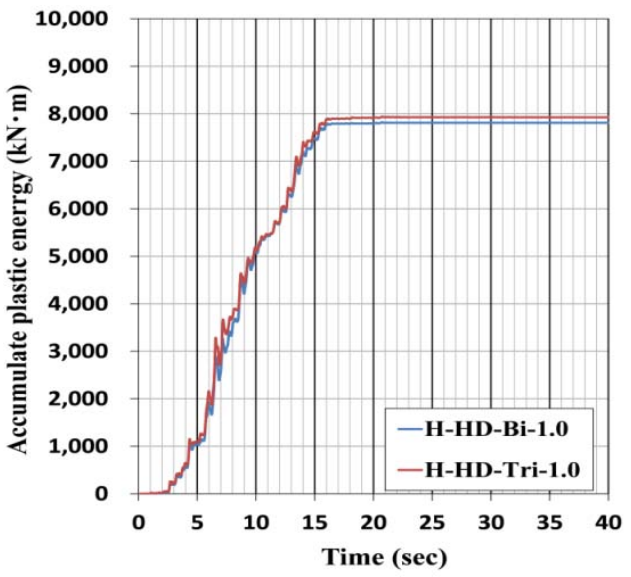

Fig. 19: Accumulate plastic energyon bilinear model and trilinear model (II-II-1)

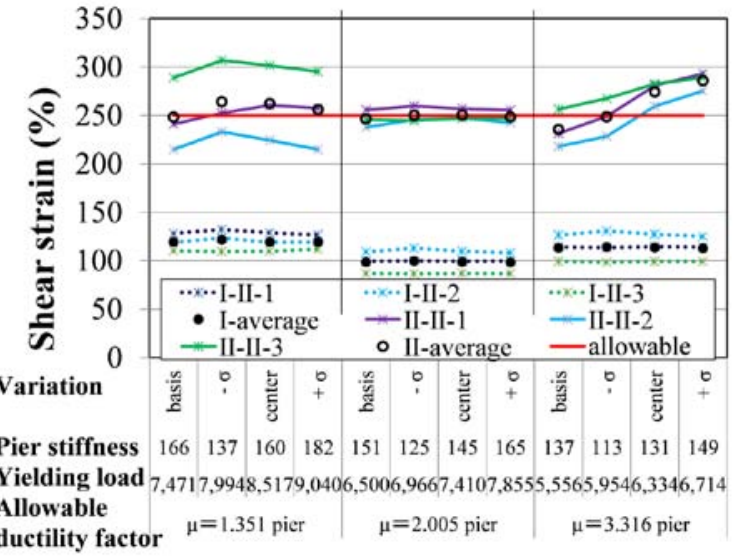

(a) Maximum shear strain of LRB
Table 9: Pier for investigating over strength



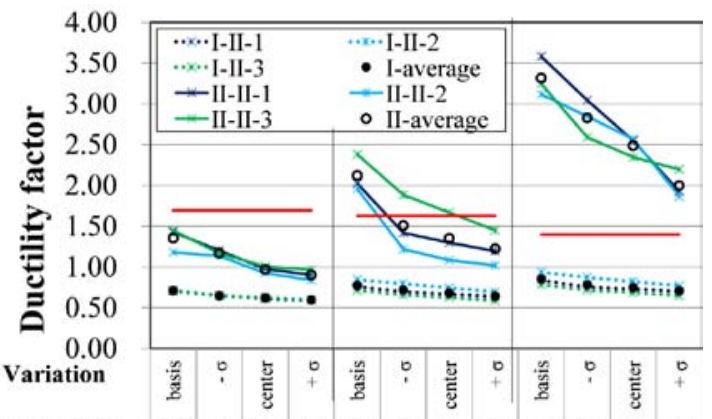

$\begin{array}{llllllllllllllll}\text { Pier stifness } & 166 & 137 & 160 & 182 & 151 & 125 & 145 & 165 & 137 & 113 & 131 & 149\end{array}$ Yielding load $7,4717,9948,5179,0406,5006,9667,4107,8555,5565,9546,3346,714$ Allowable

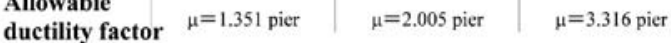

(b) Maximum ductility ratio of pier

Fig. 20: Response including influence of over strength

c) Effect on the maximum shear strain of $L R B$

As shown in Fig. 20, since the pier behaves elastically in Type I, the pier yield load does not affect the maximum shear strain of LRB. However, because the yield stiffness and over strength are increasing at the same time, the maximum shear strain of LRB changes slightly. The following is a review of the response of Type II. In Fig. 20, in the pier with $\mu=1.351$, the maximum shear strain of LRB increases as the yield load becomes $-\sigma$ to the standard value, but at the average value, $+\sigma$, the yield load increases and the shear strain decreases. In contrast, the $\mu=2.005$ pier has an overall constant shear strain of LRB. Finally, for a pier with $\mu=3.316$, the yield load and the maximum shear strain of LRB are proportional. In general, when the pier is plasticized, the maximum acting force of the rubber bearing becomes large, depending on the yield load of the pier. For this reason, the maximum shear strain of LRB of a pier with large plasticization and $\mu=3.316$ is consistent with the general behavior. On the other hand, when the yield load of the pier increases, the maximum ductility factor of the pier necessarily decreases. As a result, the maximum ductility factor of pier with $\mu=3.316$ at large plasticization decreases linearly due to the increase in the yield load of the pier. However, the trends of the pier 
with $\mu=1.351$ and pier with $\mu=2.005$ are different. The reason is that at the pier with $\mu=1.351$, the average yield load and the maximum ductility factor of $+\sigma$ are less than 1.0 and have the elastic response. That is, since the pier is not plasticized, the yield load of the pier does not directly affect the maximum shear strain of

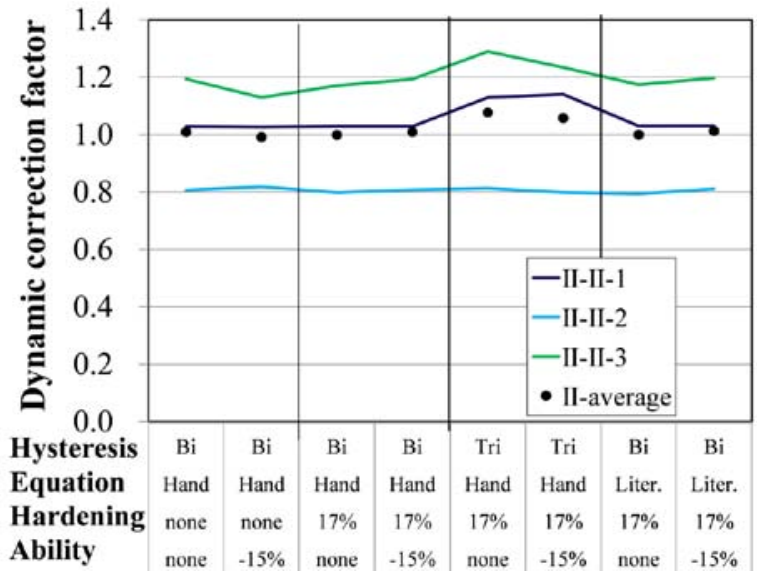

(a) Response by rigid reduction and individual hysteresis of LRB
LRB. The pier with $\mu=2.005$ is in a plasticized state due to over strength, but the maximum shear strain of LRB shows a different result from that of the pier with $\mu=3.316$ because there is little change due to over strength.

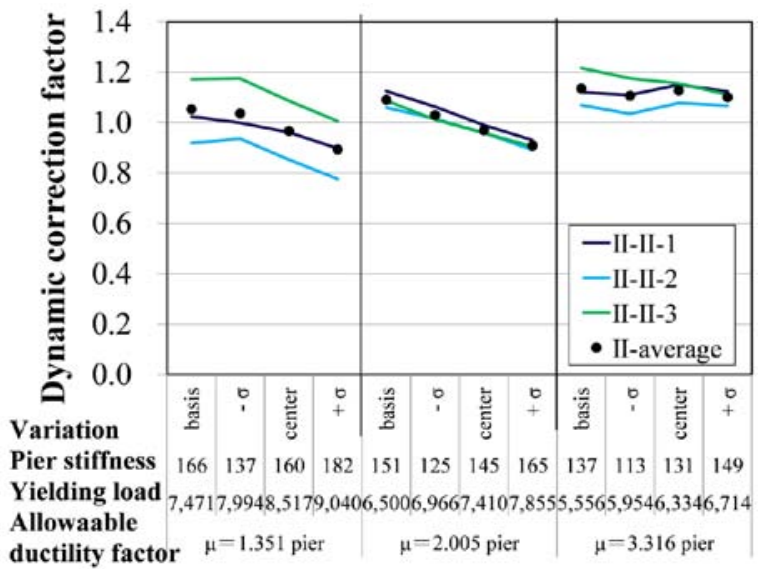

(b) Response including influence of over strength of pier

\section{Fig. 21: Dynamic correction factor}

\section{d) Dynamic correction factor}

The dynamic correction factor is calculated by dividing the maximum resistance force of LRB by the yield load of the pier. When the pier with $\mu=3.316$ in Fig. 21(b) is plasticized, the dynamic correction factor does not change significantly even if the yield load of the pier increases. In contrast, the dynamic correction factors for pier with $\mu=1.351$ and $\mu=2.005$ decrease with increasing yield load. In addition, when the yield load is the average value and $+\sigma$, the dynamic correction factor is less than 1.0, which means that LRB acting force is less than the yield load. In $\mu=1.351$ pier, the pier behaves elastically and $\mu=2.005$ pier is plasticized, but the force acting on LRB is smaller than the yield load. For this reason, the increase in yield load did not significantly affect the maximum shear strain of LRB. This factor is considered to be caused by the inertia of the pier itself and the vibration mode of the second or higher order.

\section{e) Evaluation of $L R B$ for over strength}

In the seismic isolation bridge, the plasticization of the lower part of the pier is suppressed. However, it was confirmed that the maximum shear strain of the bearing did not necessarily increase even if the yield load increased due to over strength. Since the specifications of the designed bridge are varied, the effects of over strength are different. Therefore, it is necessary to investigate the effect of over strength on the response for each bridge. Meanwhile, the dynamic correction factor in Fig. 21(a) is a vibration system using a pier with $\mu=1.351$, and there is little change in the dynamic correction factor due to the elastic response of the seismic wave. On the contrary, when the hardening of LRB is analyzed with a trilinear model, the dynamic correction factor is increasing. This is because the force on the pier was increased by the trilinear model. As a result, it is larger than the case of applying the bilinear model.

\section{f) Effect of over strength to the lower part of the pier}

In general, the yield load of the lower part of the pier is designed to be more than 1.1 times the yield load of the pier, so that the lower part of the pier does not yield before the pier. However, if the yield load of the lower part of the pier is exceeded due to over strength, there is a concern that the lower part of the pier will yield first. Fig. 22 shows the relationship between the bending moment and the yield bending moment of the lower part of the pier considering the over strength of the pier. As a result, the bending moment of the lower part of the pier is difficult to increase and slightly exceeds 1.1 times the yield bending moment of the pier without the effect of over strength. Therefore, the maximum shear strain of LRB of the seismic isolation bridge, where plasticization of the pier is suppressed, is not affected by the overstrength, but it is necessary to consider the safety of the lower part of the pier separately.

\section{Vil. Influence of Dispersion in Multi-Span Girders}

\section{a) Pier model to be reviewed}

The framework of the girders of the two single column bridge piers and four single pillar pier supporting superstructure, which are the models to be 
reviewed is shown in Fig.23. For this model, the effect of the stiffness change of LRB between piers on the load distribution was analyzed for each case. The specifications of the pier model are the same as those used in this paper. The stiffness of LRB was set by increasing or decreasing to 1.30 times and 0.85 times the maximum value of the design based on reference 11) and combined in Tab. 10 for each pier. The hysteresis shape was set as a bilinear model as shown in Fig. 24. Here, the cross-sectional area of the girders installed between piers is $0.6085 \mathrm{~m} 2$ according to reference 14).

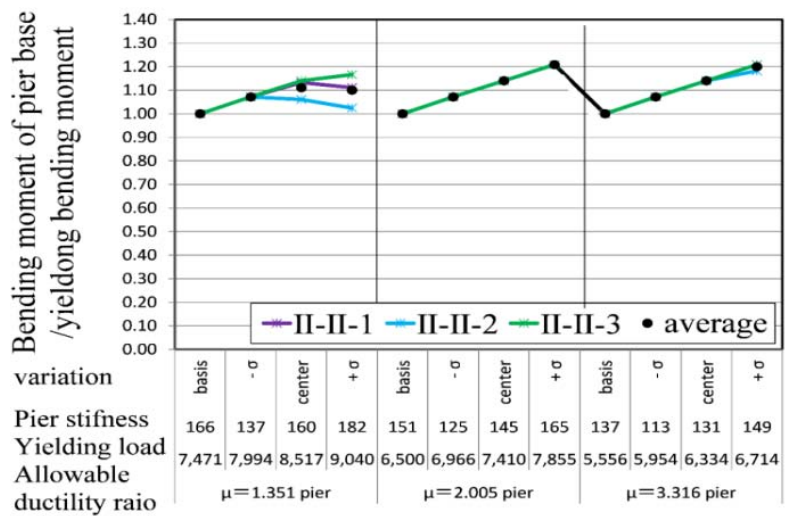

Fig. 22: Maximum bending moment of over strengthened pier with $\mu=1.351$

b) Effect of response history and dispersion between piers

The response history of LRB and the history of the lower part of the pier are shown in Fig. 25 and Fig. 26. The shear strain of LRB of the 0.85 model $(0.85)$ is larger than that of the 1.00 model (1.00) without stiffness change and smaller than that of the 1.30 model (1.30). However, the shear strain of 0.85 does not increase in the case where the 1.30 model increases from the four pier models to three. This is considered to be because the inertia force of the superstructure is concentrated at 1.30. On the other hand, the response of the lower part of the pier is largely plasticized in the 1.30, but plasticization hardly occurs in the 0.85 . In particular, in the case of one 1.30 among the four pier models, an extremely large plasticization occurs because most of the inertia force of the superstructure is concentrated only in this pier. However, the response change of LRB is not much different compared to the plasticization of the lower part of the pier. This means that it is difficult to concentrate the load on LRB due to the plasticization of the pier, but the seismic energy is largely consumed as the plasticization of the lower part of the pier proceeds. The time history response resistance waveform of LRB and the time history response curvature at the lower part of the pier are shown in Fig. 27 and 28. In the time history response waveform, there is no significant difference in the resistance waveform of each model's LRB. In contrast, the curvature of the time history response at the lower part of the pier varies greatly for each pier. Particularly, when the residual variation at the 1.30 pier is large and there is only one 1.30 model, quite large residual variation occurs. The comparison of the shear strain of LRB, the bending moment of the lower part of the pier, and the ductility factor of the lower part of the pier between models are shown in Fig. 29, Fig. 30 and Fig. 31, respectively. From this, it can be seen that when the rigidity of the 1.30 model and LRB is increased, the response of LRB decreases, but on the contrary, the plasticization of the lower part of the pier becomes large. In conclusion, if there is a difference in the performance of LRB for each pier, it gives a significant effect in the plasticization of LRB and the lower part of the pier, and has a greater effect on the pier. Although the results of this research are extreme cases, it is desirable to make LRB installed at each pier in the same manufacturing process as much as possible so that there is no difference in performance of LRB.

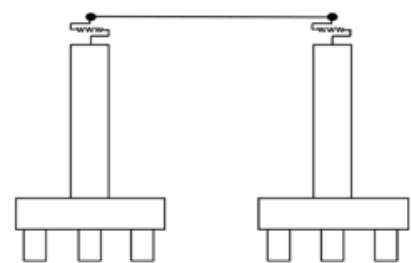

(a) 2 piers model
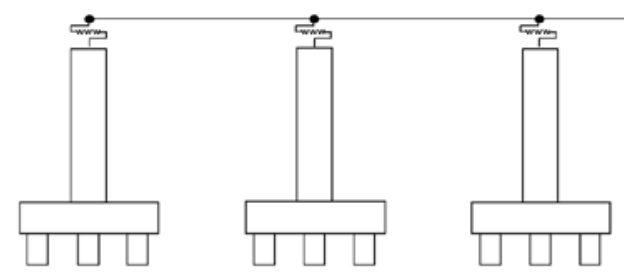

(b) 4 piers model

Fig. 23: Dispersion effect review model of multi span girder 
Table 10: Stiffness of LRB on each pier

\begin{tabular}{|c|c|c|c|c|c|c|c|}
\hline \multicolumn{2}{|c|}{} & P1 & P2 & P3 & P4 & \multicolumn{2}{c|}{ Notation for each pier } \\
\hline \multirow{2}{*}{$\begin{array}{c}\text { 2-piers } \\
\text { model }\end{array}$} & -1 & 1.00 & 1.00 & - & - & \multicolumn{2}{c|}{ P1, P2 : H-Li-Bi-2M P1·P2-1.00 } \\
\cline { 2 - 8 } & -2 & 0.85 & 1.30 & - & - & P1 : H-Li-Bi-2M P1-0.85 & P2 : H-Li-Bi-2M P2-1.30 \\
\hline \multirow{4}{*}{$\begin{array}{c}\text { 4-piers } \\
\text { model }\end{array}$} & -1 & 1.00 & 1.00 & 1.00 & 1.00 & \multicolumn{2}{|c|}{ P1, P2, P3, P4 : H-Li-Bi-4M Pall-1.00 } \\
\cline { 2 - 8 } & -2 & 0.85 & 1.30 & 1.30 & 1.30 & P1 : H-Li-Bi-4M -P1-0.85 & P2,P3,P4 : H-Li-Bi-4M P2·P3·P4-1.30 \\
\cline { 2 - 8 } & -3 & 0.85 & 0.85 & 0.85 & 1.30 & $\begin{array}{c}\text { P1, P2, P3 : H-Li-Bi-4M -P1·P2·P3- } \\
0.85\end{array}$ & P4 : H-Li-Bi-4M P4-1.30 \\
\hline
\end{tabular}



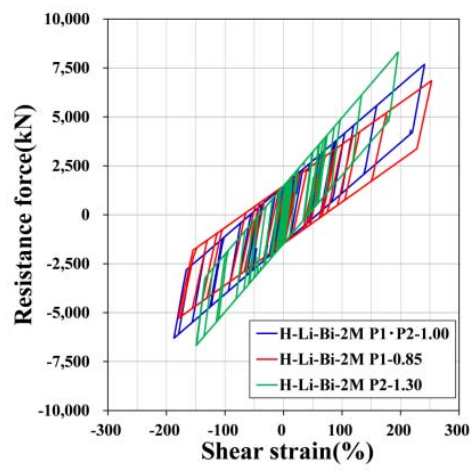

P1:0.85 - P2:1.30model

(a)2-piers model

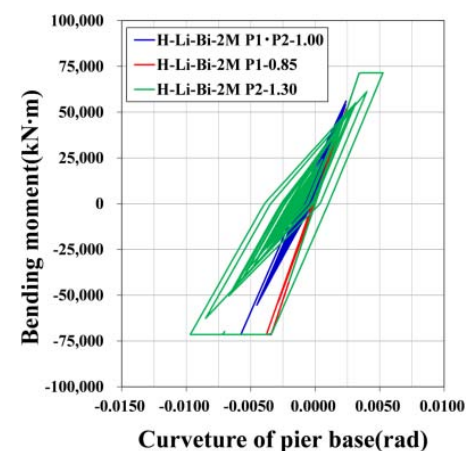

P1:0.85 - P2:1.30model

(a)2-piers model
Fig. 24: Hysteresis of LRB on $250 \%$

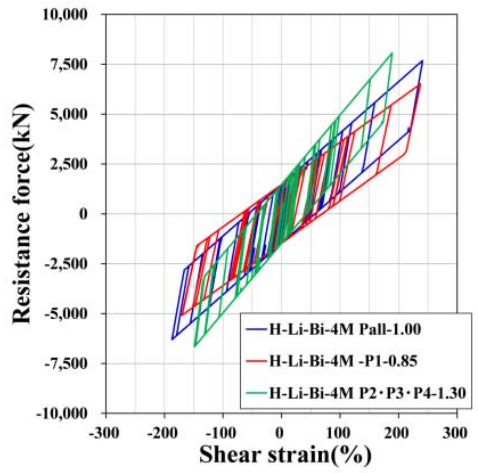

P1:0.85 - P2· P3· P4:1.30model
Fig. 25: Hysteresis of LRB
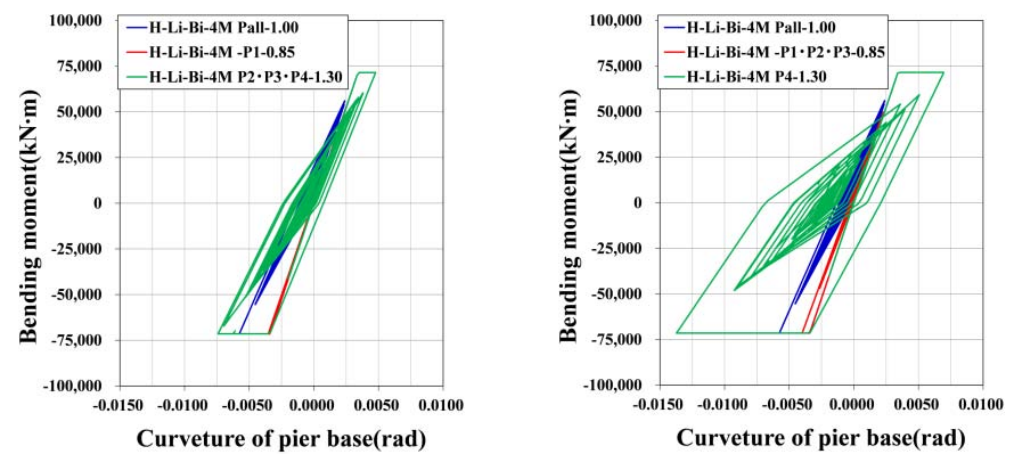

P1:0.85 - P2· P3· P4:1.30model



P1·P2. P3:0.85 - P4:1.30model 4-piers model

P1·P2· P3:0.85 - P4:1.30model (b) 4-piers model

Fig. 26: Hysteresis of pier base 


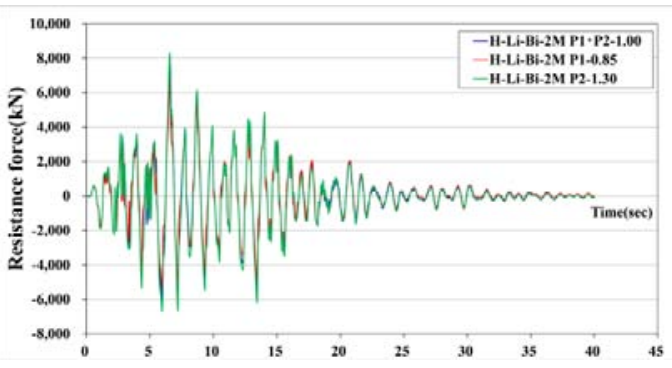

(a) 2-piers modelP1:0.85 - P2:1.30model

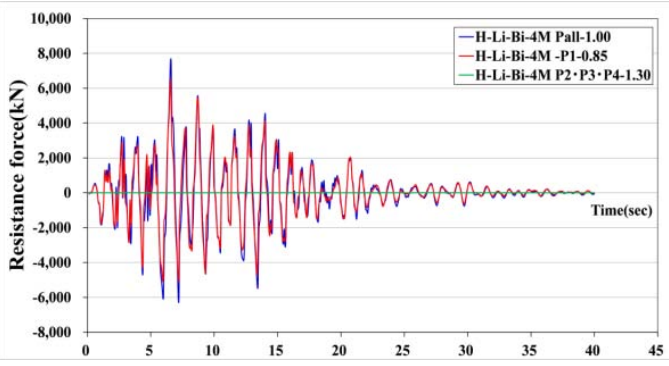

(b) 4-piers modelP1:0.85 - P2. P3. P4:1.30model

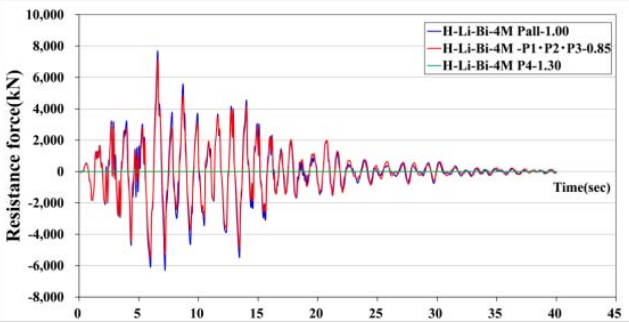

(c) 4-piers modelP1· P2 P3:0.85 -P4:1.30model

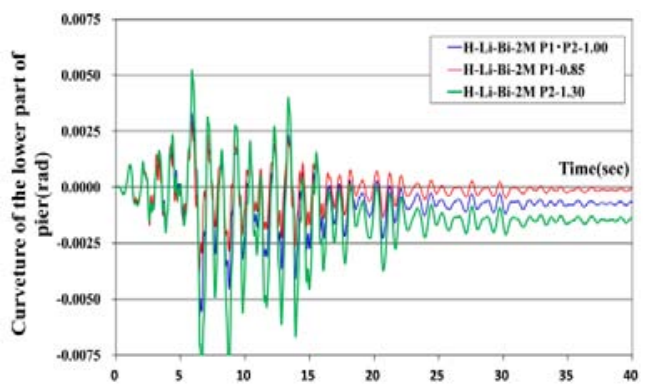

(a) 2-piers modelP1:0.85 - P2:1.30mode

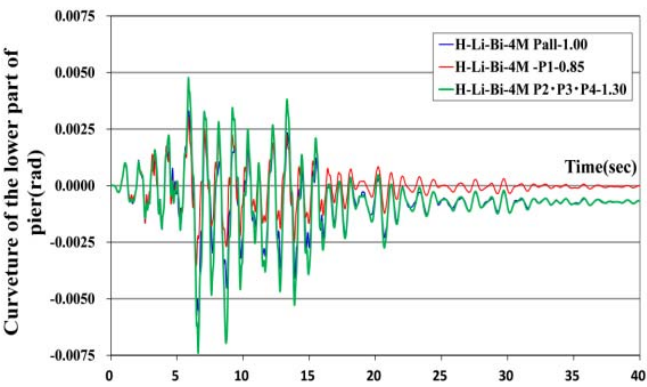

(b) 4-piers modelP1:0.85 - P2. P3. P4:1.30model

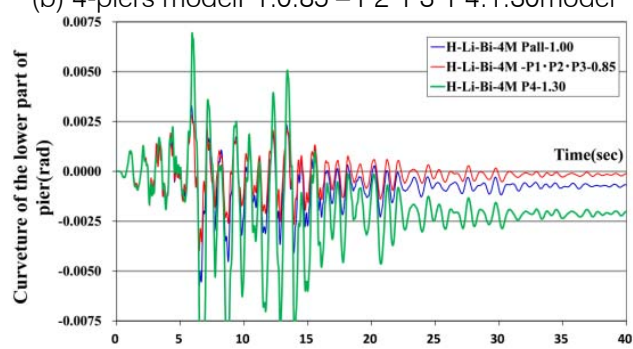

(c) 4-piers modelP1· P2· P3:0.85 -P4:1.30model

Fig. 27: Historical resistance force of LRB

Fig. 28: Historical curvature of pier base
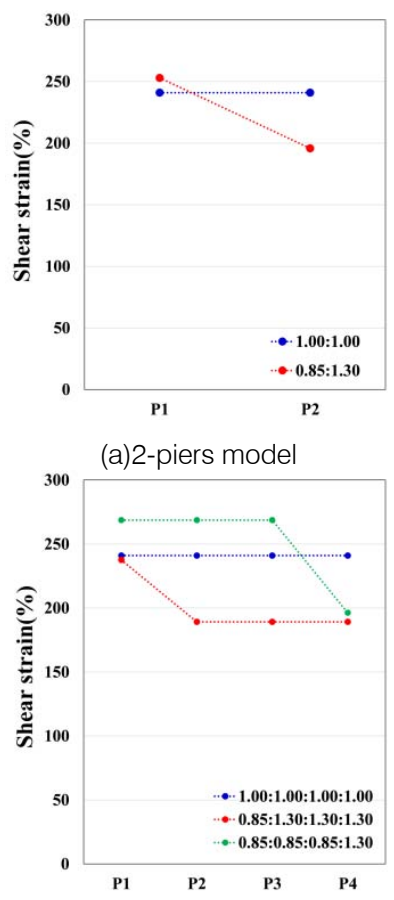

(b)4-piers model

Fig. 29: Shear strain of LRB


(b)4-piers model

Fig. 30: Bending moment of pier

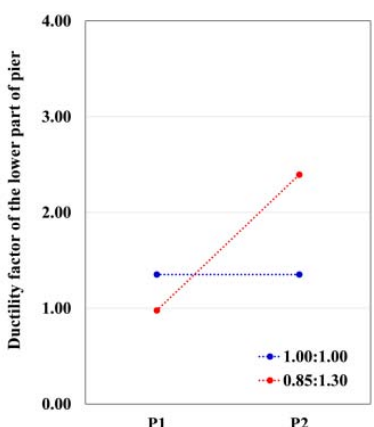

(a)2-piers model

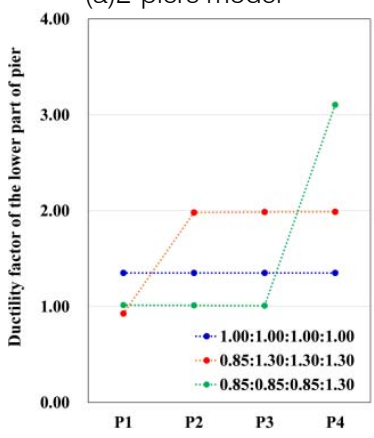

(b)4-piers model

Fig. 31: Ductility factor of pier base 


\section{Vili. COnClusion}

Based on the analysis results presented in this paper, the main conclusions are as follows:

1. Considering the hardening of LRB in the current design reduces the maximum shear strain of LRB. In the current design, the maximum shear strain is about $250 \%$, but in the bilinear model and the trilinear model considering hardening, it is reduced to $200 \%$ and $230 \%$, respectively. In general, as in this paper, when considering hardening, the maximum shear strain of LRB is set to be larger for the trilinear model than for the bilinear model.

2. Suppose the maximum shear strain of LRB is designed to be $250 \%$ according to the current design, considering the decrease in stiffness of $15 \%$, the maximum shear strain of LRB increases to about $300 \%$, so there is a risk of fracture. However, the hardening phenomenon must occur and it becomes difficult to fracture because the shear strain is reduced to about $250 \%$ when considered in the bilinear model. In contrast, in the trilinear model, the shear strain is about $270 \%$, which is greater than the allowable shear strain $250 \%$. In conclusion, when designing in consideration of hardening, it is necessary to review the modeling method of hardening.

3. It is necessary to understand that in a seismic isolation bridge, the predominant period depends not only on the difference in seismic waves but also on LRB hysteresis setting and nonlinearity.

4. When the allowable ductility factor of the pier is set to be small, such as a seismic isolation bridge, it is expected that the effect of the over strength of the pier on the maximum shear strain of LRB is small. On the contrary, in the design of plasticizing piers largely, it is necessary to pay attention to the increase in the maximum shear strain of the bearings due to the over strength of the piers. Based on the results presented in this paper, it was confirmed that LRB performance in the current design of LRB is difficult to become larger than the expected response in the design due to the hardening occurring in the high deformation region even if the stiffness decreases due to various dependencies or durability. In addition, in the seismic isolation design with limited plasticization of the pier, the effect of the over strength of the pier was found to be small. In conclusion, it means that when the seismic isolation design according to the current design is applied in the actual design, the response of LRB due to the performance change of the bearing (LRB) or the over strength of the pier does not significantly exceed the allowable shear deformation.

5. If the stiffness of LRB between piers is different from the design value, the response of LRB with small stiffness increases due to the difference, or the piers with LRB with high stiffness are large plasticized. This means that it is different from the expected value of the design. There are various factors for fluctuations in LRB between piers. Therefore, it is important to manufacture in the same manufacturing process as LRB used in the same pier in order not to cause a relative difference in LRB between piers.

\section{AFTERWORD}

In this paper, LRB seismic safety was evaluated in cases where the stiffness of LRB is smaller than the design stiffness and the yield load of the pier is increased by selecting a single column pier model in a bridge using LRB. In this regard, if the stiffness of LRB is greater than the design expected, there is a possibility that a large inertia force acts on the pier and the safety of the pier is lost when the earthquake occurs. However, in general, the design of piers has a greater allowance during an earthquake than LRB, and the yield load of piers due to over strength is greater than the value determined in the design. In addition, since the earthquake safety factor of the seismic isolation designed pier is twice that of the distributed bearing $(\mathrm{RB})$, it is thought that there is a large allowance for the safety during an earthquake, but it is important to note that an earthquake behavior of the seismic isolation bridge is not necessarily guaranteed. For this reason, it is necessary to evaluate the safety of the pier by increasing the response of the pier of the seismic isolation bridge. In addition, a case study was conducted on the effect of the stiffness change of LRB between piers on the dispersion of the inertia force of the continuous girder. Depending on the pier, there are various factors that affect the stiffness of LRB. Therefore, it is important to manufacture LRB in the same manufacturing process so that stiffness does not change. In this paper, the statically indeterminate force due to temperature change and the characteristics of the foundation were not verified as factors that increase the response of the seismic isolation bearing. Among them, temperature change is a clearly occurring phenomenon, and if the length of the extension girder is long, like a multi-span continuous girder bridge, the effect on the earthquake response at low and high temperatures is clearly evident. Most of the statically indeterminate force is generated by plasticizing the pier, which increases the ductility factor and residual displacement of the pier, and also increases the response variation and residual displacement of the bearing. This means that bridges that are likely to have increased the statically indeterminate force need to check their behavior during an earthquake in the state of deformation when the temperature changes. In addition, since the temperature change affects the hysteresis characteristics of the bearing, it is preferable to use the 
hysteresis shape in consideration of these factors. However, in general, it is not necessary to consider a bridge that is not long because the temperature change has a small effect on the response during an earthquake. On the other hand, the variation in the dispersion of the inertia force of the continuous girder is likely to be influenced by the performance variation of the seismic isolation bearing of the pier. Therefore, in order to reduce the relative performance fluctuation between the seismic isolation bearings, it is necessary to make the manufacturing lot of the seismic isolation bearing used in the bridge almost identical. As a result, it can be expected that the effect on the horizontal force distribution of the continuous girder is reduced and the behavior is difficult to damage during an earthquake determined in the structural design [8]. The influence of the characteristics of the foundation of the ground is expected to vary widely. Therefore, since it is difficult to set design conditions, it is necessary to prevent ground fluctuations from affecting the response during an earthquake through secondary plasticization of piers like a seismic isolation bridge.

\section{Appendix}

Formula for $R_{k}$ in East, Central and West Japan Expressway co., Ltd. Construction Management Guidelines [11]

$R_{k+}$

$$
\begin{gathered}
=+\sqrt{\left(R_{k(\text { Initial })}\right)^{2}+\left(R_{k(\text { Period })}\right)^{2}+\left(R_{k(\text { Temperature })}\right)^{2}+\left(R_{k(\text { pressure })}\right)^{2}} \\
+\left(R_{k(\text { Compression fatigue })}\right)+\left(R_{k(\text { Shear fatigue })}\right) \leq 0.30
\end{gathered}
$$

$R_{k-}$

$$
\begin{gathered}
=-\sqrt{\left(R_{k(\text { Initial })}\right)^{2}+\left(R_{k(\text { Period })}\right)^{2}+\left(R_{k(\text { Temperature })}\right)^{2}+\left(R_{k(\text { pressure })}\right)^{2}} \\
+\left(R_{k(\text { Compression fatigue })}\right)+\left(R_{k(\text { Shear fatigue })}\right) \geq-0.1
\end{gathered}
$$

Where each $R_{k}$ is the ratio representing the change in various factors.

\section{References Références Referencias}

1. Japan Road Association. (2012). Design Specifications for Highway Bridges part 5, Seismic Design.

2. Japan Road Association. (2004). Manual for Highway Bridges Bearings.

3. NAITO N, MAZDA T, UNO H, KAWAKAMI M. (2017). Seismic Performance Evaluation of LRB Considering Mullins Effect and Hardening. Proc. Of JSCE Vol.73, No. 4, I 499-I 510

4. MAZDA T, UNO H, MIYAMOTO $\mathrm{H}$, YUNOKI $\mathrm{K}$. (2008). Evaluation on dynamic response of bridges considering expansion and contraction of girder. Proc. of Japan Concrete Institute, Vol.30, No.3, pp.1039-1044

5. UNO $\mathrm{H}$, MAZDA T, MIYAMOTO $\mathrm{H}$, YUNOKI $\mathrm{K}$, CHOU S, SHINODA R (2010). Influences to Seismic Behavior for Isolation Bridge and Non-Isolation Bridge under Temperature Changes, Proc. of the 13th Symposium Tokyo, Japan Association for Earthquake Engineer

6. Steel Road Bridge Research Committee of Hokkaido Civil Engineering Society, (2012). Part1 Design and Construction, Design and Construction Guidelines for Steel Road Bridges in Hokkaido.

7. NAKAMURA K, IMAI T, OKUI Y, SATO T. (2016). Characteristic Value at Ambient Temperature Considering Self-heating and Study of Temperature rise During Earthquake of High Damping Rubber
Bearing. Proc. of the 71th JSCE Annual Meeting, I-215.

8. Road Management Technology Center (1995) Handbook on Design and Execution of No-Joint construction Methods for existing bridges.

9. KOSAKA A, INOUE K, SENDA T, HICHIDO H, IMAI T. (2013). Experimental Study on Durability of Lead Rubber Bearing for Road Bridges. Proc. of the 58th JSCE Annual Meeting, I-371.

10. HICHINOHE H, KUJI S, UNO H, KOSAKA A, IMAI T. (2013). Experimental Study on Performance Stability of Lead Rubber Bearing for Road Bridges. Proc. Of the 58th JSCE Annual Meeting, I-370.

11. East, Central and West Japan Expressway co., Ltd. (2016, Jul 12). Standard Specifications for Structure Construction Management.

12. TAKAHASHI $Y$, SHINOHARA S, HOSIKUMA J. (2014). Upgrading of Seismic Isolation Bearing Analysis Model. Proc. ofthe17th Symposium on Performance-based Seismic Design Method for Bridges.

13. ADACHI Y, UNJOH S. (2000). Effect of Variations in Equivalent Stiffness and Damping Coefficient of Isolation Bearing on Seismic Response Characteristics of Road Bridges. Proc. Of the 4th Symposium on Ductility Design Method for Bridges, JSCE

14. Japan Road Association. (1997). Reference for Highway Bridge Seismic Design. 